\section{(6) OPEN ACCESS}

${ }^{1}$ Nottingham Respiratory Research Unit, University of Nottingham, Nottingham, UK 2Nuffield Department of Medicine, University of Oxford, Oxford, UK

\section{Correspondence to} Dr Tim Harrison, Nottingham Respiratory Research Unit, University of Nottingham, Clinical Sciences Building, Nottingham City Hospital, Hucknall Road, Nottingham NG5 1PB, UK; tim.harrison@nottingham.ac.uk

Received 28 October 2014 Revised 1 February 2015 Accepted 15 March 2015 Published Online First 9 April 2015

\title{
A randomised controlled trial of small particle inhaled steroids in refractory eosinophilic asthma (SPIRA)
}

\author{
David Hodgson, ${ }^{1}$ John Anderson, ${ }^{1}$ Catherine Reynolds, ${ }^{1}$ Garry Meakin, ${ }^{1}$ Helen Bailey, ${ }^{1}$ \\ lan Pavord, ${ }^{2}$ Dominick Shaw, ${ }^{1}$ Tim Harrison ${ }^{1}$
}

\begin{abstract}
Background Some patients with refractory asthma have evidence of uncontrolled eosinophilic inflammation in the distal airways. While traditional formulations of inhaled steroids settle predominantly in the large airways, newer formulations with an extra-fine particle size have a more peripheral pattern of deposition. Specifically treating distal airway inflammation may improve asthma control.

Methods 30 patients with refractory asthma despite high dose inhaled corticosteroids were identified as having persistent airway eosinophilia. Following 2 weeks of prednisolone $30 \mathrm{mg}$, patients demonstrating an improvement in asthma control were randomised to receive either ciclesonide $320 \mu \mathrm{g}$ twice daily or placebo in addition to usual maintenance therapy for 8 weeks. The primary outcome measure was sputum eosinophil count at week 8. Alveolar nitric oxide was measured as a marker of distal airway inflammation.

Results There was continued suppression of differential

\section{Key messages}

What is the key question?

- Does treatment with an extra-fine particle size inhaled steroid reduce airway eosinophilia in patients with ongoing sputum eosinophilia despite high dose inhaled steroids?

What is the bottom line?

- Sputum eosinophils improved significantly in patients who did not change their baseline maintenance steroid dose, but markers of distal airway inflammation did not change significantly.

Why read on?

- Patients with persistent airway eosinophilia are not refractory to treatment, and targeting this group with higher doses of steroid is likely to be beneficial.
\end{abstract} sputum eosinophil counts with ciclesonide (median $2.3 \%$ ) but not placebo (median 4.5\%) though the between-group difference was not significant. When patients who had changed their maintenance prednisolone dose during the trial were excluded the difference between groups was significant (1.4\% vs $4.5 \%, p=0.028$ ). Though alveolar nitric oxide decreased with ciclesonide the value did not reach statistical significance.

Conclusions These data demonstrate that patients with ongoing eosinophilic inflammation are not truly refractory, and that suppression of airway eosinophilia may be maintained with additional inhaled corticosteroid. Further work is needed with a focus on patient-orientated outcome measures such as exacerbation rate, with additional tests of small airway function.

Trial registration number NCT01171365. Protocol available at http://www.clinicaltrials.gov.

\section{INTRODUCTION}

Patients with asthma are heterogeneous in terms of inflammation in the airway and response to antiinflammatory treatment. Most patients with asthma CrossMark

To cite: Hodgson $D$,

Anderson J, Reynolds C,

et al. Thorax 2015;70:

559-565. have predominantly eosinophilic inflammation, which responds to a relatively small dose of inhaled corticosteroid (ICS). ${ }^{1}$ There are patients however, who continue to exhibit eosinophilic airway inflammation despite high dose inhaled steroid, ${ }^{2}$ and who have more marked impairment of lung function, evidence of airway remodelling, and a higher risk of severe or fatal asthma exacerbations. ${ }^{3-5}$ The mechanism underlying this persistent inflammation is not clear, but it is not totally steroid resistant, as high dose parenteral steroids have been shown to abolish airway eosinophilia in patients who have ongoing inflammation despite high dose ICS. ${ }^{6}$ Non-adherence to inhaled treatment is the explanation for a large number of these cases, but other factors probably contribute.

One possible explanation is that systemic steroids reach the small airways $(<2 \mathrm{~mm}$ in diameter) that are not treated by traditional formulations of ICS. They have been largely ignored until recently, partly because they are more difficult to assess than the larger proximal airways, but also because they were not thought to contribute significantly to airflow obstruction. Improvements in imaging and immunohistochemical techniques have provided a growing body of data to support the idea that the peripheral airways are sites of significant inflammation and physiological dysfunction in asthma, ${ }^{7-13}$ and that current first-line inhaled anti-inflammatory formulations are not delivering the drug to the distal parts of the lung. ${ }^{14-16}$

Steroid probably needs to be deposited in the large and small airways to achieve optimal therapeutic effect. The distribution of an ICS within the airway is related to particle size. Higher rates of peripheral deposition are seen as the particle size gets smaller with an optimum size of 
1.0-1.2 $\mu \mathrm{m} .{ }^{17}$ While older metered dose inhalers (MDIs) which used chlorofluorocarbons (CFCs) as propellants had a relatively large median particle size, newer MDIs use hydrofluoroalkanes (HFAs) which generate extra-fine particles and improve total lung deposition. ${ }^{18}$

This pilot study was designed to determine whether the introduction of extra-fine ICS could maintain the beneficial effects seen from a 2-week course of oral prednisolone in patients on high dose inhaled steroids. To maximise our chances of success we initially phenotyped patients and only included those with evidence of persistent eosinophilic inflammation.

\section{METHODS}

Subjects meeting the ATS criteria for refractory asthma with evidence of ongoing eosinophilic inflammation (sputum differential cell count $\geq 3 \%$ or blood eosinophils $\geq 0.4 \times 10^{9} / \mathrm{mL}$ ) were recruited from difficult asthma clinics in Nottingham and Leicester between November 2010 and August 2013. ${ }^{19}$ Exclusion criteria included active smoking or a smoking history in excess of 10 pack-years, allergic bronchopulmonary aspergillosis or clinically significant bronchiectasis. All potential participants provided written informed consent and were assessed for treatment adherence using prescribing records from primary and secondary care. Baseline measurements were taken of bronchial and alveolar exhaled nitric oxide (NO), Juniper Asthma Control Questionnaire (ACQ) score, Juniper Asthma Quality of Life Questionnaire (AQLQ) score, and spirometry including bronchodilator reversibility.

All potential trial participants $(n=32)$ were given treatment with 2 weeks of prednisolone $30 \mathrm{mg}$ daily and assessed for clinical improvement prior to randomisation. Clinical improvement was defined as any one of:

- Normalisation $(<25 \mathrm{ppb})$ or a reduction in concentration of exhaled $\mathrm{NO}$ of $\geq 40 \%,{ }^{20}$

- An increase in prebronchodilator forced expiratory volume in $1 \mathrm{~s}\left(\mathrm{FEV}_{1}\right)$

- An improvement in Juniper ACQ score of $\geq 0.5$ points. $^{22}$

Subjects who met these criteria $(n=30)$ underwent further sputum induction, and were then randomised in a double-blind manner to receive either ciclesonide $320 \mu \mathrm{g}$ twice daily or placebo for 8 weeks in addition to their usual maintenance medication; including high dose ICS with or without low dose oral prednisolone. Randomisation was performed in permuted blocks of 10 by the University of Nottingham Clinical Trials Unit. Subjects underwent instruction and assessment of inhaler technique with the trial drug MDI, and those that were unable to achieve an adequate technique with additional instruction $(n=4)$ were issued an AeroChamber Plus (GSK, Middlesex, UK).

The primary outcome measure was the change in sputum differential eosinophil count between randomisation and week 8. Secondary outcome measures were ACQ score, AQLQ score, prebronchodilator $\mathrm{FEV}_{1}$, bronchial $\mathrm{NO}$ and alveolar $\mathrm{NO}$ at week 8. Safety outcome measures included adverse events and serum cortisol level at week 8 . Subjects attended trial visits at week 4 and week 8, with assessment of secondary outcome measures and adverse events at both visits and further sputum induction at week 8. Subjects attended a final follow-up visit at week 12 to reassess secondary outcome measures and adverse events after discontinuation of the trial drug.

\section{Exhaled NO}

Measurement of exhaled NO levels was performed using the NIOX Flex (Aerocrine AB, Solna, Sweden). Exhaled NO levels were measured at multiple flows $(10 \mathrm{ml} / \mathrm{s}, 30 \mathrm{ml} / \mathrm{s}, 50 \mathrm{ml} / \mathrm{s}$,
$100 \mathrm{ml} / \mathrm{s}, 200 \mathrm{~mL} / \mathrm{s})$. Exhaled bronchial $\mathrm{NO}$ at $50 \mathrm{~mL} / \mathrm{s}\left(\mathrm{Fe}_{\mathrm{NO}}\right)$ was taken as the mean value of two blows. Alveolar NO concentration $\left(\mathrm{C}_{\mathrm{alv}}\right)$ was corrected for axial back diffusion as described by Kerckx et al. ${ }^{23}$ Two adequate blows at three different flow rates were considered the minimum required to calculate a value for alveolar NO.

\section{Lung function}

Spirometry was performed as per American Thoracic Society/ European Respiratory Society guidelines, ${ }^{24}$ using a Vitalograph Gold Standard wedge bellows spirometer (Vitalograph, Buckingham, UK). Subjects were instructed to omit their shortacting bronchodilators for $4 \mathrm{~h}$ and their long-acting bronchodilators for $12 \mathrm{~h}$ prior to the study visit. For reversibility testing salbutamol was administered as $4 \times 100 \mu \mathrm{g}$ inhalations from an MDI via a spacer device, with repeat spirometry after a minimum of $15 \mathrm{~min}$.

\section{Asthma control and quality of life}

Asthma control was assessed using a self-completed ACQ questionnaire. A score of $\geq 1.5$ was used to define poorly controlled asthma, as this is safely within the uncontrolled range, and is the lowest value at which a clinically significant change in score takes the subject into the 'controlled' range. ${ }^{22}$ Quality of life was assessed using a self-completed AQLQ questionnaire. ${ }^{25}$

\section{Sputum differential cell count}

Inflammatory phenotyping was performed using sputum induction to obtain a differential cell count. The protocol for sputum induction and processing has been previously described, ${ }^{26}$ and uses a low-output ultrasonic nebuliser to deliver hypertonic saline at increasing concentrations. Subjects were classed as eosinophilic if their differential sputum eosinophil count was $\geq 3 \%$. $^{27}$

\section{Statistical analysis}

Statistical analysis was performed using Stata SE V.11.2 (Statacorp, Texas, USA). Data for exhaled NO $\left(\mathrm{Fe}_{\mathrm{NO}}\right)$ were log transformed to normality prior to analysis. Corrected alveolar NO, differential cell counts for blood and sputum and serum cortisol could not be transformed to normality and were analysed as non-parametrical data. Based on data with a similar cohort of patients, ${ }^{6} 16$ patients per group would allow detection of a $40 \%$ reduction in sputum eosinophil count at $80 \%$ power, assuming a median sputum eosinophil count at baseline of $25 \%$. We planned to recruit 20 patients per group to allow for dropouts.

Within-group change was assessed using a paired samples $t$ test for parametrical data and a Wilcoxon signed-rank test for nonparametrical data. Between group differences were assessed using an independent samples $t$ test for parametrical data and a Mann-Whitney U test for non-parametrical data. Changes in logtransformed values for $\mathrm{Fe}_{\mathrm{NO}}$ were expressed as fold change using the antilog of the mean difference, along with the 95\% CI.

Due to the short nature of the study participants on oral prednisolone were asked to avoid changing their maintenance dose during the study. Unfortunately five patients did change their maintenance dose during the trial period and so a post hoc, per-protocol analysis was performed evaluating patients who maintained a stable maintenance dose throughout the trial.

\section{RESULTS}

Forty-seven patients were approached to take part in the study between December 2010 and August 2013. Thirteen subjects were excluded as they did not have evidence of persistent 
eosinophilic inflammation. Two subjects did not meet our prespecified criteria for a clinical response to prednisolone, and a further two subjects declined to take part. Thirty subjects were randomised to receive ciclesonide $(\mathrm{n}=15)$ or placebo treatment $(n=15)$ and 29 completed all of the study visits (figure 1). Recruitment was closed before the target of 40 patients was reached due to expiry of active and placebo inhalers.

Prior to treatment with prednisolone the two groups were comparable (table 1). Subjects were already receiving high dose inhaled steroid (median $1600 \mu \mathrm{g}$ of BDP or equivalent daily) and a third were using maintenance prednisolone. For the patient group as a whole there was a significant improvement in sputum eosinophil count, lung function, asthma control and quality of life after 2 weeks of prednisolone (table 2, figure 2).

Twenty-four out of 30 subjects $(80 \%)$ were able to provide a second sputum sample at week 8 . The median sputum eosinophil count in the ciclesonide group was $2.3 \%$ (IQR $0.5-13.5 \%$ ), an increase of $2.3 \%$ from the postprednisolone value $(p=0.263)$. In the placebo group the median sputum eosinophil count at week 8 was $4.5 \%$ (IQR range $1.0-9.5 \%$ ), an increase of $4.5 \%$ from the postprednisolone value $(p=0.041)$. Though ciclesonide maintained sputum eosinophils at $<3 \%$ the between-group difference was not significant $(p=0.317$; table 3 , figure 3). There was a trend towards lower corrected alveolar NO in the ciclesonide group at week 8 , but the difference did not reach statistical significance.

There was no significant decline in lung function, asthma control, quality of life or exhaled NO in either group (table 3).
Though there was a trend towards worsening asthma control in the placebo group this was not significant (change in ACQ 0.7, $\mathrm{p}=0.051$ ). Ciclesonide was well tolerated, with no dropouts due to adverse effects and no significant suppression of serum cortisol (median change from baseline $-62 \mathrm{nmol} / \mathrm{L}, \mathrm{p}=0.327$ vs $+34 \mathrm{nmol} / \mathrm{L}$ in the placebo group, $\mathrm{p}=0.953)$. Though more subjects in the placebo group reported worsening breathlessness or wheeze in the 8 -week trial period (4 vs 1 in the ciclesonide group) this was not significant.

\section{Effect of change in maintenance steroid}

Although all subjects were requested to try and keep their maintenance dose of oral prednisolone constant during the study, five subjects (three in the placebo group and two in the ciclesonide group) were taking a higher than usual maintenance dose of steroid at the week 8 visit. In addition, one subject in the ciclesonide group felt well enough to stop their maintenance steroid dose during the trial period and experienced an exacerbation just before week 8 (see figure 3 ). As this is very likely to have an effect on the outcome measures for airway inflammation at week 8 an additional per-protocol analysis was performed excluding these patients.

Again, there was a significant rise in sputum eosinophils over 8 weeks with placebo $(4.5 \%, p=0.014)$ which was not seen in the ciclesonide group (table 4 ) and the between-group difference was significant $(p=0.028)$. There remained no significant differences between groups for any of the secondary outcome measures.

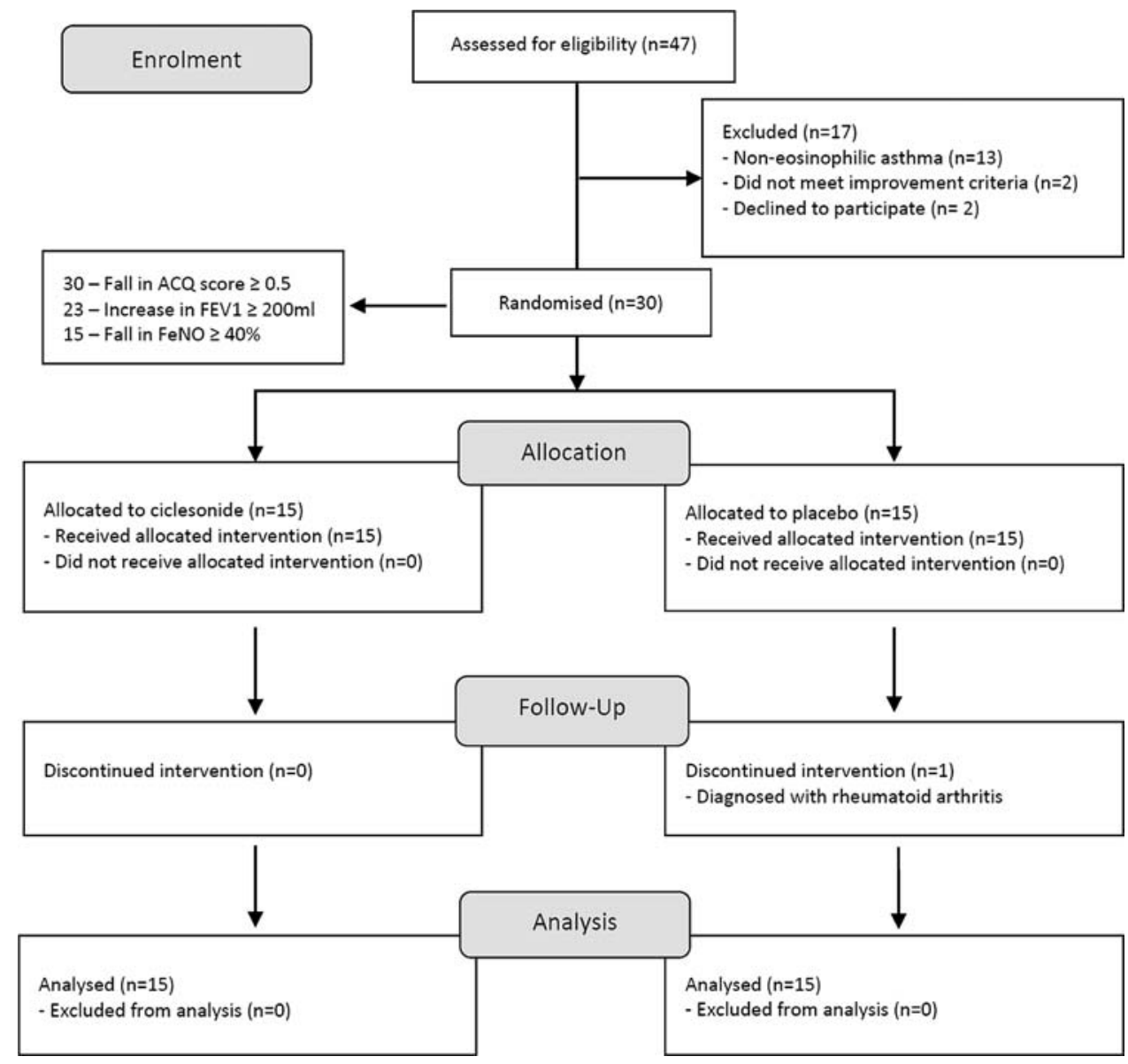

Figure 1 Consort flow diagram. Two patients in the run-in period did not reach our prespecified criteria for clinical improvement despite a reduction in sputum eosinophils. One patient in the placebo group dropped out in week 3 but was included in the final intention-to-treat analysis. 
Table 1 Baseline characteristics

\begin{tabular}{|c|c|c|}
\hline & Ciclesonide $(n=15)$ & Placebo $(n=15)$ \\
\hline Age (years)* & $48.5(11.6)$ & $53.3(13.3)$ \\
\hline Female (\%) & $7(47 \%)$ & $7(47 \%)$ \\
\hline $\mathrm{BMI}^{*}$ & $29.9(4.6)$ & $27.3(4.6)$ \\
\hline ICS dose $(\mu \mathrm{g}$ BDP $) \dagger$ & $1600(1200-2000)$ & $1600(1000-2000)$ \\
\hline Regular prednisolone (\%) & $6(40 \%)$ & $4(27 \%)$ \\
\hline Prednisolone dose $(\mathrm{mg}) \dagger$ & $5(5-10)$ & $5(5-10)$ \\
\hline $\mathrm{FEV}_{1}(\mathrm{~L})^{*}$ & $2.0(0.6)$ & $1.8(0.6)$ \\
\hline $\mathrm{FEV}_{1}(\% \text { predicted })^{*}$ & $61.8(14.9)$ & $60.1(9.4)$ \\
\hline ACQ score* & $3.2(1.0)$ & $2.8(0.8)$ \\
\hline AQLQ score* & $4.0(1.1)$ & $4.3(1.1)$ \\
\hline $\mathrm{Fe}_{\mathrm{NO}}(\mathrm{ppb}) \mp$ & $58.9(0.3)$ & $43.7(0.3)$ \\
\hline Corrected alveolar NO (ppb)† & $3.3(0.6-6.4)$ & $2.6(1.4-4.5)$ \\
\hline Sputum eosinophils (\%)† & $23(7.5-51.1)$ & $9.6(6.8-31.5)$ \\
\hline Sputum neutrophils (\%)† & $43.5(27.5-73.0)$ & $50.5(31.8-70.5)$ \\
\hline Blood eosinophils $\left(\times 10^{9} / \mathrm{L}\right) \dagger$ & $0.5(0.5-0.9)$ & $0.4(0.2-0.7)$ \\
\hline Blood neutrophils $\left(\times 10^{9} / \mathrm{L}\right) \dagger$ & $4.5(3.6-6.3)$ & $5.0(3.7-6.6)$ \\
\hline Serum cortisol (nmol/L)† & $266(217-414)$ & 254 (191-294) \\
\hline \multicolumn{3}{|c|}{$\begin{array}{l}{ }^{*} \text { Mean (SD). } \\
\text { †Median (IQR). } \\
\text { ҒGeometric mean (log SD). } \\
\text { ACQ, Asthma Control Questionnaire; AQLQ, Asthma Quality of Life Questionnaire; } \\
\text { BDP, beclometasone dipropionate; BMI, body mass index; Fe }{ }_{\text {NO, fractional exhaled nitric }} \\
\text { oxide; FEV } \text {, forced expiratory volume in } 1 \mathrm{~s} \text {; ICS, inhaled corticosteroid; NO, nitric oxide. }\end{array}$} \\
\hline
\end{tabular}

\section{DISCUSSION}

The run-in data from this study demonstrates that subjects with persistent eosinophilic inflammation remain responsive to additional corticosteroid, and that 2 weeks of systemic corticosteroids largely eliminates airway eosinophilia while improving asthma control, quality of life and lung function. These changes are unlikely to be fully explained by poor inhaler technique or non-adherence to treatment, as these factors were accounted for before the subjects were entered into the trial. The benefits seen in the run-in period with oral prednisolone were maintained after 8 weeks with the addition of ciclesonide to regular maintenance therapy whereas sputum eosinophilia was reappearing in patients treated with placebo. When changes to oral maintenance

Table 2 Response to 2 weeks of prednisolone during the run-in period for all subjects $(n=30)$

\begin{tabular}{|c|c|c|c|}
\hline & $\begin{array}{l}\text { Baseline } \\
\text { (preprednisolone) }\end{array}$ & $\begin{array}{l}\text { Randomisation } \\
\text { (postprednisolone) }\end{array}$ & p Value \\
\hline $\begin{array}{l}\text { Sputum } \\
\text { eosinophils }(\%)^{*}\end{array}$ & $\begin{array}{l}16(7.3-38.0) \\
(n=29)\end{array}$ & $\begin{array}{l}0(0-2.3) \\
(n=21)\end{array}$ & $<0.001$ \\
\hline $\begin{array}{l}\text { Sputum } \\
\text { neutrophils }(\%)^{*}\end{array}$ & $\begin{array}{l}44.5(31.8-70.5) \\
(n=29)\end{array}$ & $\begin{array}{l}78.3(56.9-94.0) \\
(n=21)\end{array}$ & 0.005 \\
\hline $\mathrm{FEV}_{1}$ (litres)† & $1.9(0.6)$ & $2.4(0.7)$ & $<0.001$ \\
\hline ACQ scoret & $3.0(0.9)$ & $1.5(0.9)$ & $<0.001$ \\
\hline AQLQ scoret & $4.1(1.1)$ & $5.6(1.1)$ & $<0.001$ \\
\hline $\mathrm{Fe}_{\mathrm{NO}}(\mathrm{ppb}) \ddagger$ & $50.9(0.3)$ & $31.7(0.3)$ & $<0.001$ \\
\hline $\begin{array}{l}\text { Corrected alveolar } \\
\text { NO }(p p b)^{*}\end{array}$ & $2.7(1.3-6.4)$ & $1.9(0.9-2.9)$ & 0.049 \\
\hline \multicolumn{4}{|c|}{$\begin{array}{l}{ }^{*} \text { Median (IQR). } \\
\text { †Mean (SD). } \\
\text { ₹Geometric mean (log SD). } \\
\text { ACQ, Asthma Control Questionnaire; AQLQ, Asthma Quality of Life Questionnaire; } \\
\text { Fe } \mathrm{N}_{\mathrm{NO}} \text {, fractional exhaled nitric oxide; FEV } \mathrm{F}_{1} \text {, forced expiratory volume in } 1 \mathrm{~s} \text {; } \\
\text { NO, nitric oxide. }\end{array}$} \\
\hline
\end{tabular}

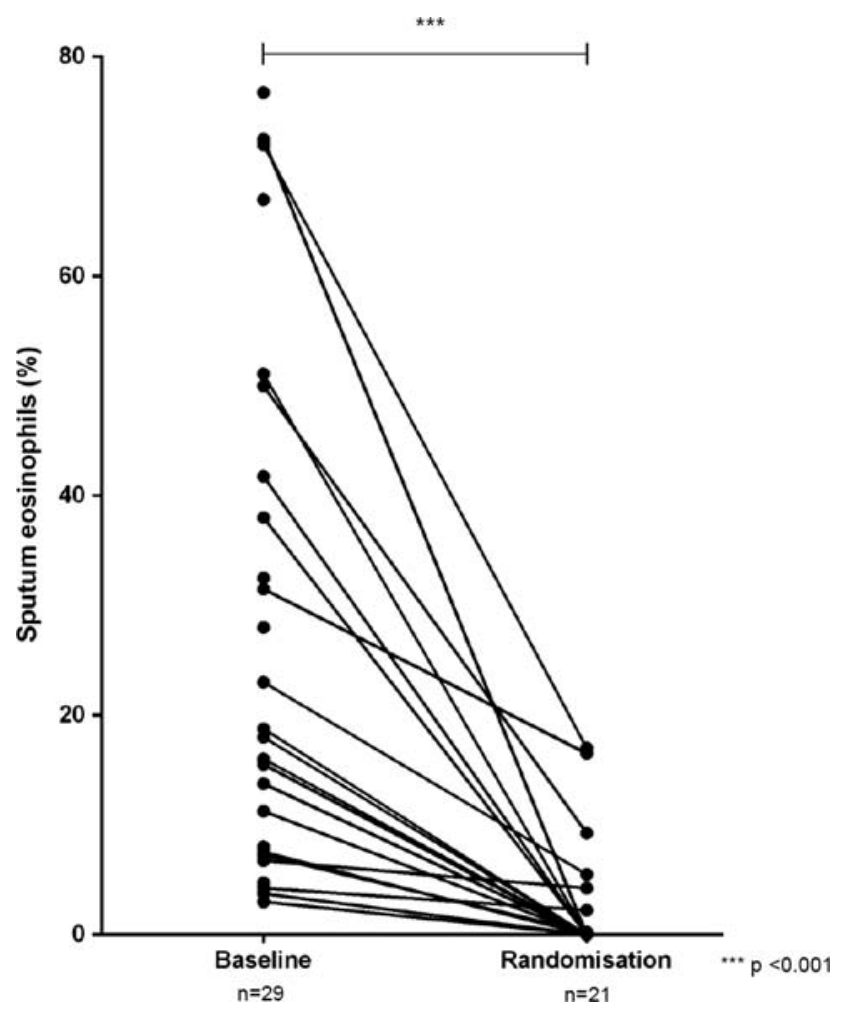

Figure 2 Sputum eosinophil count before and after 2 weeks of prednisolone.

therapy were accounted for there was significantly less airway eosinophilia with ciclesonide compared with placebo.

The main limitations of our study include its size, duration and the lack of a third limb containing standard formulation inhaled steroid. Studying patients with severe asthma is difficult and so before attempting a much larger, longer study, powered to see a difference in asthma control, we felt it was essential to first demonstrate proof of concept in a pilot study using the proxy marker of sputum eosinophilia. The beneficial effects from the addition of high dose inhaled ciclesonide on sputum inflammation may simply result from the addition of more inhaled steroid. There is however limited evidence of a dose response curve for standard inhaled steroids after approximately $1000 \mu \mathrm{g}$ beclometasone dipropionate (BDP) or equivalent, ${ }^{28} 29$ and patients in our study were already using up to $4000 \mu \mathrm{g}$ daily. We, therefore, postulate that the beneficial effects on sputum eosinophilia seen here could be secondary to the introduction of a fine-particle inhaled steroid, with improved deposition throughout the lung including the distal airways. We included measurements of alveolar NO to explore this hypothesis further but the results were inconclusive and do not help differentiate a small airway from a more general antiinflammatory effect. We did not include other markers of small airway dysfunction as none have been validated and most are relatively difficult to use in patients with more severe asthma.

The evidence for distal airway disease in some patients with difficult to control asthma is compelling. Patients with predominantly nocturnal asthma have evidence of marked eosinophilic inflammation in the distal, but not the proximal airways when biopsy samples are compared, with a fourfold increase in alveolar eosinophils correlating with worsening lung function and an increase in symptoms. ${ }^{13}$ This is not accompanied by an increase in peripheral blood eosinophils, suggesting it is an accumulation in the alveolar tissue rather than a general 
Table 3 Primary and secondary outcome measures at randomisation and week 8

\begin{tabular}{|c|c|c|c|c|c|c|c|}
\hline & \multicolumn{3}{|c|}{ Ciclesonide $(n=15)$} & \multicolumn{3}{|l|}{ Placebo $(n=15)$} & \multirow[b]{2}{*}{ Between group $p$} \\
\hline & Randomisation & Week 8 & p Value & Randomisation & Week 8 & p Value & \\
\hline Sputum eosinophils (\%)* & $\begin{array}{l}0.0(0.0-2.3) \\
(n=10)\end{array}$ & $\begin{array}{l}2.3(0.5-13.5) \\
(n=11)\end{array}$ & 0.263 & $\begin{array}{l}0.0(0.0-4.3) \\
(n=11)\end{array}$ & $\begin{array}{l}4.5(1.0-9.5) \\
(n=13)\end{array}$ & 0.041 & 0.317 \\
\hline Sputum neutrophils $(\%)^{*}$ & $\begin{array}{l}77.5(47.6-96.5) \\
(n=10)\end{array}$ & $\begin{array}{l}55.8(38.8-88.5) \\
(n=11)\end{array}$ & 0.017 & $\begin{array}{l}79.5(64.5-94.0) \\
(n=11)\end{array}$ & $\begin{array}{l}70.5(56.8-89.3) \\
(n=13)\end{array}$ & 0.799 & 0.155 \\
\hline $\mathrm{FEV}_{1}$ (litres) $\dagger$ & $2.6(0.7)$ & $2.5(0.7)$ & 0.252 & $2.1(0.7)$ & $2.0(0.6)$ & 0.115 & 0.699 \\
\hline ACQ scoret & $1.4(1.1)$ & $1.8(1.4)$ & 0.175 & $1.6(0.8)$ & $2.3(1.3)$ & 0.051 & 0.318 \\
\hline AQLQ scoret & $5.8(1.0)$ & $5.4(1.5)$ & 0.145 & $5.5(1.2)$ & $5.0(1.4)$ & 0.243 & 0.800 \\
\hline $\mathrm{Fe}_{\mathrm{NO}}(\mathrm{ppb}) \ddagger$ & $32.4(0.4)$ & $40.6(0.4)$ & 0.097 & $30.7(0.3)$ & $34.9(0.3)$ & 0.292 & 0.598 \\
\hline Corrected alveolar NO (ppb)* & $1.7(0.3-2.5)$ & $1.4(0.1-3.0)$ & 0.925 & $2.0(0.9-3.1)$ & $2.4(1.1-3.6)$ & 0.730 & 0.528 \\
\hline Blood eosinophils $\left(\times 10^{9} / \mathrm{L}\right)^{*}$ & $0.1(0.0-0.2)$ & $0.3(0.1-0.6)$ & 0.013 & $0.2(0.0-0.4)$ & $0.3(0.2-0.5)$ & 0.065 & 0.128 \\
\hline
\end{tabular}

inflammatory response. ${ }^{30}$ There is evidence of physiological dysfunction as well as inflammation in the small airways in subjects with asthma. Wagner et $a l^{9}$ used a wedged bronchoscope with a double lumen catheter to measure airway resistance in the small airways. Subjects with asymptomatic asthma and normal spirometry were compared with control subjects, and were found to have more than a sevenfold increase in peripheral airway resistance, suggesting a degree of disease activity not detected by traditional measures of lung function. Reduction in elastic recoil, which is seen in subjects with emphysema, has also been found in patients with chronic severe asthma with normal diffusion capacity and CT appearances, likely reflecting pathological changes in the small airways. ${ }^{12}$

A number of studies have explored the effect of extra-fine particle size inhaled steroids on small airway function. In a study comparing HFA-BDP with CFC-fluticasone propionate
(FP), while both inhalers improved standard markers of airflow obstruction in patients with moderate uncontrolled asthma, only the HFA-BDP formulation improved closing volume to vital capacity ratio and residual volume, both markers of small airway dysfunction. ${ }^{31}$ Goldin et $a l^{32}$ used high resolution CT to measure lung attenuation as a surrogate marker of air trapping, and demonstrated that HFA-BDP but not CFC-BDP reduced air trapping following methacholine challenge. In a further openlabel study, Verbanck et $a l^{33}$ used multiple breath nitrogen washout to assess changes in peripheral airway function following treatment with HFA-BDP in 30 patients with stable asthma. Sixteen subjects with abnormal acinar ventilation at baseline showed significant improvement in peripheral, but not central airway function with a switch to the extra-fine steroid preparation. Yamaguchi et $a l^{34}$ used impulse oscillation to assess small airway function in steroid naive patients with asthma, who were
Figure 3 Median (IQR) sputum eosinophil count before and after 8 weeks of ciclesonide or placebo in addition to usual treatment.

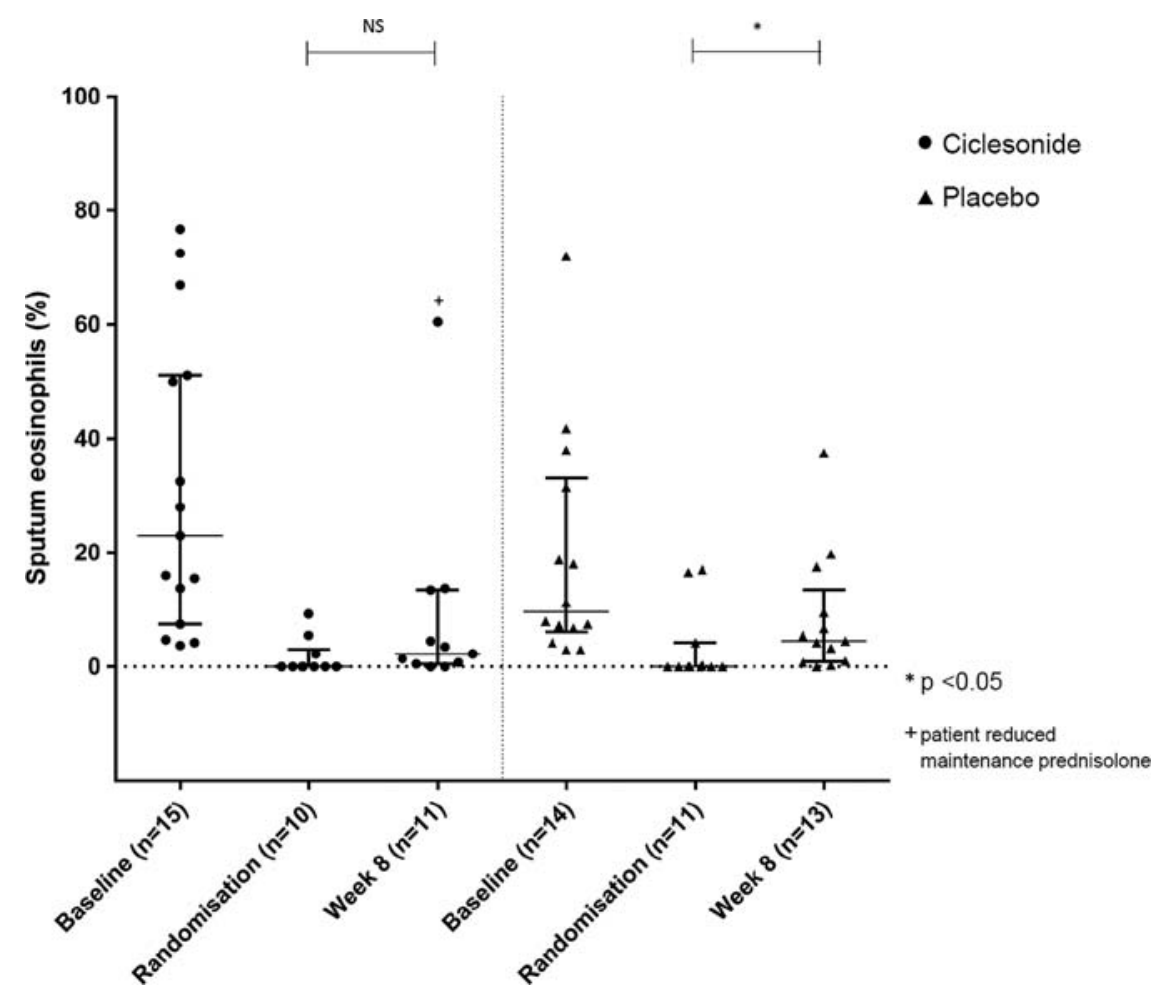


Table 4 Primary and secondary outcome measures at randomisation and week 8 for subjects with no change in maintenance prednisolone dose

\begin{tabular}{|c|c|c|c|c|c|c|c|}
\hline & \multicolumn{3}{|c|}{ Ciclesonide $(n=12)$} & \multicolumn{3}{|l|}{ Placebo $(n=12)$} & \multirow[b]{2}{*}{ Between group $p$} \\
\hline & Randomisation & Week 8 & $\mathrm{p}$ Value & Randomisation & Week 8 & $\mathrm{p}$ Value & \\
\hline Sputum eosinophils (\%)* & $\begin{array}{l}0.0(0.0-2.3) \\
(n=8)\end{array}$ & $\begin{array}{l}1.4(0.5-3.5) \\
(\mathrm{n}=9)\end{array}$ & 0.499 & $\begin{array}{l}0.0(0.0-2.3) \\
(n=8)\end{array}$ & $\begin{array}{l}4.5(1.0-17.5) \\
(n=11)\end{array}$ & 0.014 & 0.028 \\
\hline Sputum neutrophils $(\%)^{*}$ & $\begin{array}{l}85.5(62.2-96.9) \\
(n=8)\end{array}$ & $\begin{array}{l}58.0(51.2-88.5) \\
(n=9)\end{array}$ & 0.028 & $\begin{array}{l}84.0(77.1-91.6) \\
(n=8)\end{array}$ & $\begin{array}{l}70.5(56.5-90.0) \\
(n=11)\end{array}$ & 0.400 & 0.297 \\
\hline FEV1 (litres)† & $2.5(0.7)$ & $2.6(0.8)$ & 0.692 & $2.1(0.7)$ & $2.0(0.7)$ & 0.157 & 0.225 \\
\hline ACQ scoret & $1.5(1.1)$ & $1.5(1.3)$ & 0.779 & $1.5(0.8)$ & $1.9(1.1)$ & 0.186 & 0.281 \\
\hline AQLQ scoret & $5.8(0.9)$ & $5.5(1.5)$ & 0.295 & $5.5(1.1)$ & $5.5(1.2)$ & 0.826 & 0.658 \\
\hline $\mathrm{Fe}_{\mathrm{NO}}(\mathrm{ppb}) \ddagger$ & $27.8(0.3)$ & $32.9(0.3)$ & 0.241 & $26.4(0.3)$ & $29.7(0.2)$ & 0.359 & 0.787 \\
\hline Corrected alveolar NO (ppb)* & $1.9(1.0-2.5)$ & $1.3(0.1-3.0)$ & 0.789 & $2.5(0.9-3.1)$ & $2.9(1.1-3.6)$ & 0.859 & 0.922 \\
\hline Blood eosinophils $\left(\times 10^{9} / \mathrm{L}\right)^{*}$ & $0.1(0.0-0.2)$ & $0.3(0.2-0.4)$ & 0.049 & $0.2(0.1-0.4)$ & $0.3(0.2-0.5)$ & 0.091 & 0.283 \\
\hline
\end{tabular}

randomised to receive either HFA-BDP or CFC-BDP for 12 weeks. At the end of the treatment period, while both groups showed improvements in markers of large airway disease only the patients receiving HFA-BDP showed an improvement in small airway resistance. Others have used alveolar NO to look for treatment effects on the small airways. Like us, Williamson et $a l^{35}$ found that alveolar NO was insensitive to changes in dose of ICSs and Gelb et $a l^{36}$ found no change in alveolar NO with the addition of a leukotriene antagonist despite small changes in spirometry. Whether alveolar NO is a useful marker of small airway inflammation in much larger studies remains to be seen.

The extra-fine formulations appear to be safe and well tolerated, with no difference in pituitary function or urinary free cortisol excretion when compared with an equivalent dose of CFC $\mathrm{BDP}^{37}$ There is also a lower incidence of oropharyngeal candidiasis and dysphonia with extra-fine formulations, which may be due to reduced deposition of drug at these sites, ${ }^{37}$ or in the case of ciclesonide reduced drug activation outside the lung. ${ }^{16}$

The strength of this study is that we used a real-world population of patients with severe asthma. We selected patients with evidence of persistent eosinophilic inflammation, despite high-dose inhaled steroids to maximise our potential for success. Although this reduces the generalisability of our study it is in line with the current management of severe asthma which encourages the selection of patients with specific phenotypes to maximise efficacy from novel therapies. Treatment was not withheld or withdrawn during the study period, which reflects normal clinical practice, and treatment adherence was checked thoroughly before entering patients into the study. The difficulty in translating the results into clinical practice lies in the identification of patients with ongoing eosinophilic inflammation. Though induced sputum is very effective, it is relatively labour-intensive, requiring manual cell counts, and is not widely available. Though some clinicians advocate a therapeutic trial of prednisolone to identify those with residual eosinophilic inflammation it would mean overtreating many patients (in this study around $30 \%$ of patients identified had non-eosinophilic inflammation, see figure 1) and is not without risk. It may be possible to identify patients with ongoing airway eosinophilia using proxy markers such as $\mathrm{Fe}_{\mathrm{NO}}$ and blood eosinophils, but more work is required in this area.

This was a short-term, pilot study to evaluate the effect of ciclesonide in refractory eosinophilic asthma, and as such was not designed to look at outcomes such as exacerbation rate.
It has been demonstrated that a treatment strategy based on normalising sputum eosinophil count can significantly reduce asthma exacerbations and hospital admissions. ${ }^{27}$ Further work with a longer period of follow-up is needed to establish if the beneficial short-term effects of extra-fine particle size steroids translate into a longer-term reduction in exacerbations and, ultimately, a reduction in systemic steroid exposure. A third treatment arm with a higher dose of a standard formulation ICS would help to differentiate an effect on the small airways over simply more corticosteroid in the airways. If confirmed, this approach would be safer than continuing oral prednisolone and considerably cheaper than new biological therapies such as omalizumab or anti IL-5 which also reduce asthma exacerbations.

Twitter Follow David Hodgson at @dbhodgson

Acknowledgements This paper summarises independent research funded by the National Institute for Health Research (NIHR) under its Research for Patient Benefit Programme (Grant Reference Number PB-PG-0909-20101). The views expressed are those of the author(s) and not necessarily those of the NHS, the NIHR or the Department of Health. We are grateful to all trial participants who gave up their time to take part in the study, and thank Tekeda for supplying the active and placebo inhalers.

Contributors TH had full access to all of the data in the study, is the guarantor of the content of the manuscript, including the data and analysis, and takes responsibility for the integrity of the data and the accuracy of the data analysis, including any adverse effects. TH, DH, DS and IP were co-applicants on the NIHR research for patient benefit grant. $\mathrm{DH}, \mathrm{JA}$ and $\mathrm{CR}$ contributed substantially to data collection. Sputum samples were processed by $\mathrm{DH}, \mathrm{GM}$ and $\mathrm{HB}$. TH, DH, JA, CR, $\mathrm{GM}, \mathrm{HB}, \mathrm{IP}$ and DS contributed substantially to the study design, data analysis and interpretation, and the writing of the manuscript.

Funding Department of Health-National Institute for Health Research (PB-PG-0909-20101).

\section{Competing interests None declared.}

Ethics approval The study was approved by the MHRA and Nottingham Research Ethics Committee 2.

Provenance and peer review Not commissioned; externally peer reviewed.

Open Access This is an Open Access article distributed in accordance with the Creative Commons Attribution Non Commercial (CC BY-NC 4.0) license, which permits others to distribute, remix, adapt, build upon this work non-commercially, and license their derivative works on different terms, provided the original work is properly cited and the use is non-commercial. See: http://creativecommons.org/ licenses/by-nc/4.0/

\section{REFERENCES}

1 Tattersfield AE, Knox AJ, Britton JR, et al. Asthma. Lancet 2002;360:1313-22.

2 Wenzel SE, Szefler SJ, Leung DY, et al. Bronchoscopic evaluation of severe asthma. Persistent inflammation associated with high dose glucocorticoids. Am J Respir Crit Care Med 1997;156(3 Pt 1):737-43. 
3 Wenzel SE, Schwartz LB, Langmack EL, et al. Evidence that severe asthma can be divided pathologically into two inflammatory subtypes with distinct physiologic and clinical characteristics. Am J Respir Crit Care Med 1999;160:1001-8.

4 Miranda C, Busacker A, Balzar S, et al. Distinguishing severe asthma phenotypes: role of age at onset and eosinophilic inflammation. J Allergy Clin Immunol 2004;113:101-8.

5 ten Brinke A, Zwinderman AH, Sterk PJ, et al. Factors associated with persistent airflow limitation in severe asthma. Am J Respir Crit Care Med 2001;164:744-8.

6 ten Brinke A, Zwinderman AH, Sterk PJ, et al. "Refractory" eosinophilic airway inflammation in severe asthma: effect of parenteral corticosteroids. Am J Respir Crit Care Med 2004;170:601-5.

7 Martin RJ. Therapeutic significance of distal airway inflammation in asthma. J Allergy Clin Immunol 2002;109:S447-60.

8 Vignola AM, Chanez P, Campbell AM, et al. Airway inflammation in mild intermittent and in persistent asthma. Am J Respir Crit Care Med 1998;157:403-9.

9 Wagner EM, Liu MC, Weinmann GG, et al. Peripheral lung resistance in normal and asthmatic subjects. Am Rev Respir Dis 1990;141:584-8.

10 Wagner EM, Bleecker ER, Permutt $\mathrm{S}$, et al. Direct assessment of small airways reactivity in human subjects. Am J Respir Crit Care Med 1998;157:447-52.

11 Grainge CL, Lau LCK, Ward JA, et al. Effect of bronchoconstriction on airway remodeling in asthma. N Engl J Med 2011;364:2006-15.

12 Gelb AF, Zamel N, Hogg JC, et al. Pseudophysiologic emphysema resulting from severe small-airways disease. Am J Respir Crit Care Med 1998;158:815-19.

13 Kraft M, Djukanovic R, Wilson S, et al. Alveolar tissue inflammation in asthma. Am J Respir Crit Care Med 1996;154:1505-10.

14 Richards J, Hirst P, Pitcairn G, et al. Deposition and pharmacokinetics of flunisolide delivered from pressurized inhalers containing non-CFC and CFC propellants. J Aerosol Med 2001;14:197-208.

15 Leach C, Davidson P, Boudreau R. Improved airway targeting with the CFC-free HFA-beclomethasone metered-dose inhaler compared with CFC-beclomethasone. Eur Respir J 1998;12:1346-53.

16 Newman S, Salmon A, Nave R, et al. High lung deposition of 99mTc-labeled ciclesonide administered via HFA-MDI to patients with asthma. Respir Med 2006;100:375-84.

17 Fink JB, Rau JL. New horizons in respiratory care: the pharmacology of inhaled aerosol drug therapy. Respir Care 2000;45:824-5.

18 Leach C, Colice GL, Luskin A. Particle size of inhaled corticosteroids: does it matter? J Allergy Clin Immunol 2009;124(Suppl 1):S88-93.

19 Wenzel SE. Proceedings of the ATS workshop on refractory asthma. Current understanding, recommendations, and unanswered questions. Am J Respir Crit Care Med 2000;162:2341-51.

20 Dweik RA, Boggs PB, Erzurum SC, et al. An official ATS clinical practice guideline: interpretation of exhaled nitric oxide levels (FENO) for clinical applications. Am J Respir Crit Care Med 2011;184:602-15.

21 GINA. http://www.ginasthma.com
22 Juniper EF, O'Byrne PM, Guyatt GH, et al. Development and validation of a questionnaire to measure asthma control. Eur Respir J 1999;14:902-7.

23 Kerckx Y, Michils A, Van Muylem A. Airway contribution to alveolar nitric oxide in healthy subjects and stable asthma patients. J App/ Physiol 2008;104: 918-24.

24 Miller MR, Hankinson J, Brusasco V, et al. Standardisation of spirometry. Eur Respir J 2005;26:319-38.

25 Juniper EF, Guyatt GH, Epstein RS, et al. Evaluation of impairment of health related quality of life in asthma: development of a questionnaire for use in clinical trials. Thorax 1992;47:76-83.

26 Pavord ID, Pizzichini MM, Pizzichini E, et al. The use of induced sputum to investigate airway inflammation. Thorax 1997;52:498-501.

27 Green RH, Brightling CE, McKenna S, et al. Asthma exacerbations and sputum eosinophil counts: a randomised controlled trial. Lancet 2002;360:1715-21.

28 Adams NP, Jones PW. The dose-response characteristics of inhaled corticosteroids when used to treat asthma: an overview of Cochrane systematic reviews. Respir Med 2006:100:1297-306

29 Holt S, Suder A, Weatherall M, et al. Dose-response relation of inhaled fluticasone propionate in adolescents and adults with asthma: meta-analysis. BMJ 2001;323:253-6.

30 Martin RJ, Cicutto LC, Smith HR, et al. Airways inflammation in nocturnal asthma. Am Rev Respir Dis 1991;143:351-7.

31 Thongngarm T, Silkoff PE, Kossack WS, et al. Hydrofluoroalkane-134A beclomethasone or chlorofluorocarbon fluticasone: effect on small airways in poorly controlled asthma. J Asthma 2005;42:257-63.

32 Goldin JG, Tashkin DP, Kleerup EC, et al. Comparative effects of hydrofluoroalkane and chlorofluorocarbon beclomethasone dipropionate inhalation on small airways: assessment with functional helical thin-section computed tomography. J Allergy Clin Immunol 1999;104:S258-67.

33 Verbanck $S$, Schuermans D, Paiva $M$, et al. The functional benefit of anti-inflammatory aerosols in the lung periphery. J Allergy Clin Immunol 2006;118:340-6.

34 Yamaguchi M, Niimi A, Ueda T, et al. Effect of inhaled corticosteroids on small airways in asthma: investigation using impulse oscillometry. Pulm Pharmacol Ther 2009;22:326-32.

35 Williamson PA, Short PM, Vaidyanathan S, et al. Inhaled and systemic corticosteroid response in severe asthma assessed by alveolar nitric oxide: a randomized crossover pilot study of add-on therapy. Br J Clin Pharmacol 2013;75:93-102.

36 Gelb AF, Taylor CF, Simmons M et al. Role of add-on zileuton on total exhaled, large airway, and small airway/alveolar nitric oxide in moderate-severe persistent adult asthmatics on fluticasone 250 microg/Salmeterol 50 microg. Pulm Pharmacol Ther 2009;22:516-21.

37 Thompson PJ, Davies RJ, Young WF, et al. Safety of hydrofluoroalkane-134a beclomethasone dipropionate extrafine aerosol. Respir Med 1998;92(Suppl A):33-9. 